\title{
The Meaning and Functions of qSdk and yiny as Discourse Markers in Saudi Arabic
}

\author{
Maram S. Alshammary \\ The Preparatory Year Department, Hail University, Hail, Saudi Arabia
}

\begin{abstract}
The current study aims at investigating two discourse markers that are used in Saudi Arabic, "qSdk and y'ny", against Schourup's characteristics of discourse markers which are connectivity, optionality, and non-truth conditionality. Additionally, this study investigates the pragmatic uses and procedural meanings of those discourse markers using Blakemore's procedural meaning and relevance theory as a framework. By examining two discourse markers that received less attention in other studies, the current study builds on previous literature in this field. Regarding methodology, the current study is a corpus-based study in which two corpora containing texts written in Saudi Arabic are used to extract data and evidence. The study concludes that "qSdk and yৎny" behave as discourse markers by being optional, connecting two segments together, and having no influence on the truth condition of the sentence in which they are used. The discourse marker "qSdk" serves three procedural meanings: asking for clarification, correction and making irony whereas "yৎny" serves the procedural meanings of clarification and asking for clarification. Furthermore, the use of these discourse markers makes the sentence more relevant to listeners as they need less cognitive effect to derive the pragmatic meaning of the sentence.
\end{abstract}

Index Terms - discourse markers, pragmatic functions, procedural meaning, relevance theory, Saudi dialect

\section{INTRODUCTION}

Discourse markers (DMs, henceforth) can be considered as a fertile field for linguists who have been in a disagreement concerning both the definition and approaches towards analyzing such linguistic items. In order to get indepth understanding of the rationales behind such a disagreement, Fraser (2009) argued that what is considered as a DM for a group of linguists might not be considered as so for another. For instance, Fraser himself (1999) refused to consider 'now, I mean, oh, and y 'know' as DMs although Schiffrin (1987) did. This disagreement led not only to different definitions to the same group of linguistic items but to using different labels as cue phrases, discourse connectives, discourse operators, discourse particles, pragmatic markers ...etc. Among the numerous definitions of DMs, Fraser (2009) introduced an adequate one describing DMs as "expressions occur as part of a discourse segment but are not part of the propositional content of the message conveyed, and they do not contribute to the meaning of the proposition, However, they do signal aspects of the message the speaker wishes to convey" (p. 3).

\section{A. Approaches towards the Study of DMs}

Approaches that are used to analyze meanings and functions of DMs across languages can be classified into two main approaches: coherence-based approach and relevance-based approach (Hussein, 2009). The proponents of coherence-based approach such as Schiffrin (1987), Fraser (1988, 1990, 1999, 2009), and Schourup (1999) treated DMs as linguistic devices that maintain coherence within the units of text and, therefore, contribute to its interpretation. By adopting coherence theorists' views, the sentence in (1), that is taken from Fraser (1999, p. 931) can be interpreted as the following.

(1) Sue left very late, but she arrived on time.

The DM "but" relates the second segment that contained it "she arrived on time" to the segment preceding it "Sue left very late" by a semantic relationship of contrast. The process of relating two segments using a DM achieve some level of coherence within units of the utterance. However, such coherence seems harder to be achieved without connective devices as DMs.

On the other hand, for relevance-based approach proponents such as Blakemore $(1987,1992,2002)$ and Wilson and Sperber (1994) DMs are not considered as mere devices that tie units of talk together but rather as devices that control the cognitive process of the utterance interpretation. In order to understand what is relevance first, Wilson and Sperber (1994) claimed that an "information is relevant to you if it interacts in a certain way with your existing assumptions about the world" (p.92). Therefore, the degree of relevance of a sentence to a particular hearer is determined by the contextual effects that the sentence contains as well as the cognitive effort that is required from the hearer to figure out its interpretation. Wilson and Sperber (1994) determined three contextual effects that a particular sentence may provoke: joining phenomena in the real world to create new assumptions, supporting already existing assumptions, or contrasting those assumptions.

By adopting a relevance theoretic framework, Blakemore $(1987,1992,2002)$ viewed DMs as having a procedural meaning that does not contribute to the propositional content of an utterance but guides the hearers to derive the 
contextual effect that makes the utterance more relevant to them. For instance, the sentence in (2a) taken from Blakemore (1989, p.26) can be analyzed according to relevance theory as the following.

(2) a. John is a Republican, but he is honest.

b. John is not honest.

The first segment of (2a) "John is a Republican" derives the assumption in (2b). However, the use of the DM "but" in the second segment contrasts an already existing assumption a hearer might assume that if someone is a Republican, then he is dishonest. Therefore, the procedural meaning of denial of expectations, that the DM "but" has, makes the utterance in (2a) more relevant to the hearer because it contradicts and illuminates an existing assumption.

\section{B. Characteristics of DMs}

Due to the disagreement among linguists on what can be classified as a DM and what cannot be, Schourup (1999) listed the most common characteristics that most linguists agreed upon. These characteristics include connectivity, optionality, non-truth conditionality, weak clause association, initiality, orality, and multi categorality. It is important to put into consideration that the first three characteristics highly determine what linguistic items can be considered as DMs while the last four characteristics receive less attention. Two main reasons justify why the last four characteristics are less important in determining what a DM is (Schourup, 1999). First, it is common to find DMs in written language as well as spoken language. Second, it is possible for a DM to occupy middle or final positions while serving the same functions as DMs in initial positions.

In order to understand what each characteristic means, it is beneficial to examine the DM "but" in the sentence in (3):

(3) a. John was sick but he went to school.

b. John was sick. He went to school.

If the analysis here focuses only on the first three characteristics which are connectivity, optionality, non-truth conditionality, it will be as the following. The DM "but" in (3a) connects two segments or two propositions and its optional use does not influence neither the grammaticality nor the semantic meaning of the utterance when deleted in (3b). Although, the DM "but" conveys the meaning of contrast and denial of expectations but it does not contribute to the truth condition of the utterance. This means that both utterances in (3) are true if and only if John was sick and went to school which means that whether the DM exists or not, the truth condition of the utterance is the same.

If little attention is given to the other four characteristics of DMs, it would be beneficial to analyze the sentence in (3) as the following. The characteristic of weak clause association either means that DMs do not fall inside the syntactic structure of the utterance or phonologically uttered in a way that reflects the position of a tool used only to separate two segments and do not belong to any. However, the reason behind the neglection of this characteristic in particular might be because what it conveys is a mere repetition of what is conveyed by other characteristics of optionality and non-truth conditionality. Moreover, the DM "but" occupies the initial position of the proposition it introduces. Although, "but" cannot occur in middle or final positions, other DMs can such as the DM "therefore" in (4) that was introduced by Fraser (2009, p. 6):

(4) The electricity went off. We, therefore, couldn't make dinner.

The characteristic of multi categorality means that there is no single syntactic category that embraces all DMs. Instead, DMs can belong to a number of syntactic categories such as verbs, conjunctions, clauses, or interjections.

\section{DMs across Languages}

The case of DMs is not unique to a particular language. A number of studies have been conducted to address the issue of DMs functions and meanings extensively in a number of the world's languages such as English (e.g. Blakemore 1987, 1992, 2002; Fraser 1988, 1990, 1999, 2009; Schiffrin 1987; Schourup, 1999), Spanish (e.g. Fuentes-Rodríguez et al., 2016), Chinese (e.g. Wang, 2017), French (e.g. Bouveret \& Carter-Thomas, 2019), Persian (e.g. Mohammadi, 2019), Korean (e.g. Ahn and Yap, 2020), and other languages that cannot be covered in a single study.

The diglossic situation that is found in Arab countries can be described as the use of two varieties. One variety, Standard Arabic in this case, is used for prestigious purposes such as religion and education and the other, regional varieties in this case, is used in less formal situations. Therefore, studies that analyze Arabic DMs can be classified into three categories. The first classification includes studies that analyzed DMs found only in Standard Arabic. For instance, Al Kohlani (2010), Alhuqbani (2013), Taha et al. (2014), and Alsager et al. (2020) introduced in-depth analysis of functions and meanings of 16 DMs used in Standard Arabic. On the other hand, other researchers included DMs that are used only in regional varieties of Standard Arabic such as Tunisian dialect (Adams, 2012), Iraqi dialect (Alazzawie, 2015), Saudi dialect (Alrajhi, 2019 \& Alshamari, 2015 a-b), and Jordanian dialect (Jarrah et al. 2020). The last classification includes studies that analyzed DMs found in both Standard Arabic and its varieties. For instance, Hussein (2009) used relevance-theoretic approach to analyze the Standard Arabic DMs "lakinna, bainama, lakin, bal and fa" as well as the Syrian DMs "bass, la-heik, la-ha-sabab, mYnatu and biittali”. Furthermore, Bidaoui (2015) studied 13 DMs used in Standard Arabic and two varieties which are Egyptian and Moroccan varieties. Additionally, some researchers did not focus only on the functions and meaning of DMs but also compared and contrasted Arabic DMs with others across languages such as Hussein (2009) who compared the set of DMs he studied to the English DMs "but and so". Alhuqbani (2013) and Alsager et al. (2020) also compared the Arabic DM "Lakin" to the English DM "but". 
Studies that investigated DMs in Saudi variety of Arabic (SA henceforth) are limited. Alshamari (2015a) tested three Saudi DMs, yamaar, maar and Pal-muhim, that are found especially in Haili dialect, one variety of Saudi dialect, against Schourup's characteristics of DMs (1999) and analyzed them in the light of relevance theory to determine their functions. Additionally, Alshamari (2015b) introduced syntactic as well as pragmatic analysis of the discourse functions of 17 DMs used in Haili dialect. This set of discourse markers involved "Cid, Zad, Pažal, Sumr, Pisim, Said, kumma, $\mathrm{z}$ `eli, tsan, yamaar, maar, PaӨari, Sৎa hi: h, xaTir, tsaif, Sankin, and fin”. By using relevance theory as a model for analysis as well as Schiffrin's account of DMs (1987), Alrajhi (2019) concluded that the Saudi DM "Pal hin" serves five pragmatic functions and imposes constraints on relevance. Although, a number of DMs are used in SA, only few studies were devoted to study their functions and pragmatic meanings. Thus, the current study aims at examining two linguistic items that are used in SA, qSdk and y9ny, against Schourup's characteristics of DMs to find out whether or not these items can be treated as DMs. Furthermore, this study aims at investigating the pragmatic functions and procedural meanings of these DMs in the light of relevance theory (1996) as well as Blakemore's procedural meaning (2002).

\section{Research Questions}

The current study aims at answering the following research questions:

1. To what extent do the Saudi DMs "qSdk and y\&ny" demonstrate the DMs characteristics mentioned by Schourup (1999)?

2. What are the pragmatic functions and procedural meanings of the Saudi DM "qSdk"?

3. What are the pragmatic functions and procedural meanings of the Saudi DM "yYny"?

\section{METHODOLOGY}

\section{A. Instruments}

The present study is a corpus-based study in which the instruments that were used to collect data included two corpora. The first corpus (2020) consisted of a large number of sentences written by Saudi users on Twitter. The second corpus (2018) consisted of a collection of sentences and texts written by Saudi users via a number of online platforms: blogs, forums, YouTube, Instagram, Twitter, and WhatsApp. All the examples that are found in the two corpora are derived from real language.

\section{B. Procedures}

After getting permission from the corpora designers, the researcher examined them to make a list of the lexical items that are commonly used by Saudi users and might function as DMs. Among this list, the researcher selected two lexical items, "qSdk and y\{ny", because they are the most used and the most probable to function as DMs. The researcher, then, created a list of all the sentences that have these DMs to find out their functions and meanings.

\section{DISCUSSION}

The objectives of the present study focused on testing two DMs used in SA against Schourup's DMs characteristics (1999) as well as explaining the functions and procedural meanings of these DMs. The following section provides the answer to the first research question.

\section{A. $q S d k$ and $y$ Sny and Schourup's Characteristics of DMs}

Since the first three characteristics mentioned by Schourup, connectivity, optionality, and non-truth conditionality, were considered more significant in determining what a DM is, the researcher tested "qSdk and ySny" against these characteristics. The DM "qSdk" in (5b) connects two segments: "the exchange rate" and "I get 3 riyals instead of a dollar". However, the deletion of "qSdk" in (5c) reflects that its use is optional since the truth condition of the sentence does not change as a result of its deletion. This means that both sentences in ( $5 b$ and $c)$ are true if and only if the exchange rate means that she/he gets 3 riyals instead of a dollar.

(5) a. Рəða hsabək b-Paldwlar twSl dwlar, siir kəða taxðynh b-?alriial hsb şr aS-Srf

If your account supports dollar, you get dollars otherwise you get riyals according to the exchange rate.

b. šlwn hsb şr aS-Srf? qSdk dwlar axðha riial w kəða?

What do you mean by the exchange rate? do you mean that I get 3 riyals instead of a dollar?

c. $s$ lwn hsb sir aS-Srf? dwlar axðha riial w kəða?

What do you mean by the exchange rate? I get 3 riyals instead of a dollar?

Similarly, the DM y9ny in (6a) connects one segment or thought "tomorrow is off" to another segment or thought "there is no class" by the procedural meaning it conveys. The use of y@ny is optional as its deletion does not affect the truth condition of the sentence. This means that both sentences in ( $6 \mathrm{a}$ and $b)$ are true if and only if tomorrow is off and there is no class.

(6) a. bnat bwkra off y@ny mafy klas

Tomorrow is off, this means that there is no class.

b. bnat bwkra off, mafy klas

Tomorrow is off, there is no class. 
After testing the DMs “qSdk and y९ny" against the first three characteristics of DMs mentioned by Schourup (1999), it can be concluded that, these lexical items behave as DMs. The following section answers the second research question by examining the functions and procedural meanings of the DM "qSdk".

\section{B. The Pragmatic Functions and Procedural Meanings of the Saudi DM "qSdk"}

By investigation the sentences that are found in the two corpora, it is obvious that "qSdk" conveys three procedural meanings in SA: asking for clarification, correction, and making irony. For instance, "qșdk" in (7) helps the listener to infer that the speaker finds the word "tutorial" difficult to be understood. The speaker uses the DM "qSdk" which conveys the pragmatic meaning of asking for clarification to ask the listener if the word "tutorial" means "makeup" or something else.

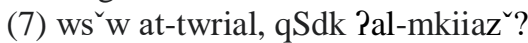

What is the tutorial? You mean makeup?

The sentence in (8) reflects the pragmatic function of correction that the DM "qșdk" conveys. In this sentence, speaker b does not ask for clarification as in the previous example. Rather, speaker b corrects the name of an application mentioned by speaker a.

(8) a. ts ‘ tkiin fii brnamž kwlna watn.

a. Make a complainment in Kwlna Wattn app.

b. Kwlna Pamn app qSdk.

b. Kwlna Amn app you mean.

The procedural meaning of correction that the DM "qSdk" conveys is also related to other DMs mentioned by other researchers such as "Lakin" in standard Arabic (Alsager et al., 2020) and "bass" in Syrian Arabic (Hussein, 2009).

The last procedural meaning of the DM "qSdk" is shown in (9). In the first sentence, speaker A describes a news channel, that is very popular in the Middle East, as funny. Speaker b, who is against the policy of this channel, makes irony by stating that the channel should be called the Hebrew Channel not the Arabian Channel as speaker b believes that the channel's attitudes are against the Arabs. Awareness of the procedural meaning that the DM "qSdk" conveys makes the listener recognizes that speaker $\mathrm{b}$ is not correcting the name of the channel but making irony.

(9) a. Wallah ?nat PalGrbyyah dmha xfiif.

a. Alarabiya channel is funny.

b. Pnat PalYibryyah qSdk.

b. The Hebrew Chanel you mean.

As noticed in the previous examples, the use of the DM "qSdk" does not add extra information to the sentences. Rather, the use of the DM "qSdk" provides the listener with information beyond the truth condition of the sentence to clarify that the speaker of (7) is asking for clarification, the speaker of (8) is correcting, and the speaker of (9) is making irony. Awareness of all the procedural meanings that are related to the DM "qSdk" allows the listener to infer the meaning of the sentence with less cognitive effort which makes the utterance more relevant.

\section{The Pragmatic Functions and Procedural Meanings of the Saudi DM "ySny"}

"yЯny", as a DM in SA, has two procedural meanings. It is used as a DM of clarification in (10).

(10) l?an qwql 50\% mn tržmth tržmh hrfiih yGny ytržm klmh klmh mws` Palžmlh klha

Because $50 \%$ of Google translation is literal translation. This means that it translates word by word not the whole sentence.

The listener's awareness of the procedural meaning of clarification that the DM "yৎny" conveys makes him realize that the second part of the sentence does not add new information. Rather, it only clarifies and explains the first part. It should be mentioned that this DM is also used in Moroccan dialect (Bidaoui, 2015) and carries the same procedural meaning of clarification.

The other procedural meaning of the DM "yৎny" is different from its procedural meaning of clarification that is found also in Bidaoui (2015). Asking for clarification is the other procedural meaning that "yৎny" conveys in (11).

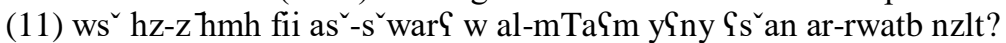

Why it is very crowded in streets and restaurants? Is it because you received your salaries?

Understanding the procedural meanings of the DM "ySny" allows the listener, with less cognitive effort" to understand that the part that follows "yৎny" is not clarifying the part that precedes it. Instead, the speaker used "y९ny" to ask for the reason that might justify this crowd. If such a DM is deleted from the sentence, the listener can infer the meaning but with more cognitive effort.

\section{CONCLUSION}

The present study sought to answer three research questions to find out whether or not we can consider two lexical items, qSdk and y9ny, that are used in SA as DMs. Based on that, the study aimed at finding the pragmatic uses and procedural meanings of these lexical items. Based on the data that were used in the present study, "qSdk and y9ny" are used as DMs in SA as they carry the same characteristics of DMs mentioned by Schourup (1999). This means that the 
use of these DMs in sentences is optional, does not influence the truth condition of the sentence, and aims to connect segments or parts of the sentence together.

Concerning the pragmatic uses and procedural meanings of these DMs, it is found that the DM "qSdk" conveys three procedural meanings of correction, asking for clarification, and making irony. Additionally, the DM "yৎny" conveys only the procedural meanings of clarification and asking for clarification. The use of DMs makes the sentence more relevant to the reader/ listener as they would be able to infer the pragmatic meaning with less cognitive effort. The current study builds on previous studies concerning the use of DMs in SA by investigating the uses and functions of DMs that received less interest in those studies.

\section{REFERENCES}

[1] Adams, C. (2012). Six discourse markers in Tunisian Arabic: A syntactic and pragmatic analysis (Order No. 1534307) [master's thesis] ProQuest, UMI Dissertations Publishing.

[2] Ahn, M. \& Yap, F. H. (2020). “That being so, but...”: An analysis of Korean kunyang as a marker of speaker's attenuated divergent stance. Journal of Pragmatics 160, 31-43. https://doi.org/10.1016/j.pragma.2019.12.010.

[3] Alazzawie, A. (2015). $؟$ adi as a discourse marker in spoken Iraqi Arabic. Theory and Practice in Language Studies 5.7, 13521360. http://dx.doi.org/10.17507/tpls.0507.06.

[4] Alhuqbani, M. N. (2013). The English but and its equivalent in Standard Arabic: Universality vs. locality. Theory \& Practice in Language Studies 3.12, 2157-2168. http://doi.org/10.4304/tpls.3.12.2157-2168.

[5] Al Kohlani, F. A. (2010). The function of discourse markers in Arabic newspaper opinion articles (Doctoral dissertation, Georgetown University). http://hdl.handle.net/10822/552822 (accessed 01/07/2020).

[6] Alrajhi, M. (2019). The Meanings and functions of Plhin in Informal Arabic in Saudi Arabia. International Journal of Linguistics, Literature and Translation (IJLLT) 2.5, 204-210.

[7] Alruily, M. (2020). Issues of dialectal saudi twitter corpus. Int. Arab J. Inf. Technol. 17.3, 367-374. https://doi.org/10.34028/iajit/17/3/10.

[8] Alsager, H. N., Afzal, N. \& Aldawood, A. A. (2020). Discourse markers in Arabic and English newspaper articles: The case of the Arabic lakin and its English equivalent but. Arab World English Journal 11.1, 154-165. https://dx.doi.org/10.24093/awej/vol11no1.13.

[9] Alshamari, M. R. (2015a). A relevance-theoretical account of three discourse markers in North Hail Arabic. Studies in Literature and Language 11.1, 6-15. http://doi.org/10.3968/7322.

[10] Alshamari, M. (2015b). Documentation of discourse-related particles in North Hail Arabic. English Linguistics Research 4.4, 44-57. http://doi.org/10.5430/elr.v4n4p44.

[11] Al-Twairesh, N., Al-Matham, R., Madi, N., Almugren, N., Al-Aljmi, A. H., Alshalan, S., ... \& Alfutamani, A. (2018). Suar: Towards building a corpus for the Saudi dialect. Procedia computer science 142, 72-82. https://doi.org/10.1016/j.procs.2018.10.462.

[12] Bidaoui, A. (2015). Discourse markers of clarification and causality in Maghrebi and Egyptian dialects: A socio-pragmatic perspective (Doctoral dissertation, University of Illinois at Urbana-Champaign). http://hdl.handle.net/2142/78639 (accessed 25/12/2020).

[13] Blakemore, D. (1987). Semantic constraints on relevance. Oxford: Blackwell.

[14] Blakemore, D. (1992). Understanding utterances. Oxford: Blackwell.

[15] Blakemore, D. (2002). Relevance and linguistic meaning: The semantics and pragmatics of discourse markers. Cambridge: Cambridge university press.

[16] Bouveret, M. \& Carter-Thomas, S. (2020). More of the same or something different? An analysis of the French discourse marker par ailleurs in academic writing. Journal of Pragmatics 156, 136-148. https://doi.org/10.1016/j.pragma.2019.04.002.

[17] Fraser, B. (1988). Types of English discourse markers. Acta Linguistica Hungarica 38.1/4, 19-33.

[18] Fraser, B. (1990). An approach to discourse markers. Journal of pragmatics 14.3, 383-398. https://doi.org/10.1016/03782166(90)90096-V.

[19] Fraser, B. (1999). What are discourse markers?. Journal of pragmatics 31.7, 931-952. https://doi.org/10.1016/S03782166(98)00101-5.

[20] Fraser, B. (2009). An account of discourse markers. International review of Pragmatics 1.2, $293-320$. http://doi.org/10.1163/187730909X12538045489818.

[21] Fuentes-Rodríguez, C., Placencia, M. E. \& Palma-Fahey, M. (2016). Regional pragmatic variation in the use of the discourse marker pues in informal talk among university students in Quito (Ecuador), Santiago (Chile) and Seville (Spain). Journal of Pragmatics 97, 74-92. https://doi.org/10.1016/j.pragma.2016.03.006.

[22] Hussein, M. M. (2009). Relevance theory and procedural meaning: the semantics and pragmatics of discourse markers in English and Arabic (Doctoral dissertation, Newcastle University). http://theses.ncl.ac.uk/jspui/handle/10443/1155 (accessed 01/07/2020).

[23] Jarrah, M., Al-Marayat, S. \& Salem, E. (2020). The discourse use of Pil?a: n'now'in Jordanian Arabic. SKASE Journal of Theoretical Linguistics 17.1, 144-156.

[24] Mohammadi, A. N. (2019). Meaning potentials and discourse markers: The case of focus management markers in Persian. Lingua 229, 1-17. https://doi.org/10.1016/j.lingua.2019.06.007.

[25] Schiffrin, D. (1987). Discourse markers. Cambridge: Cambridge University Press.

[26] Schourup, L. (1999). Discourse markers. Lingua 107.3-4, 227-265. https://doi.org/10.1016/S0024-3841(96)90026-1.

[27] Taha, K., Jarrah, M. A. \& Al-Jarrah, R. S. (2014). The discoursal Arabic coordinating conjunction wa (and). International Journal of Linguistics 6.4, 172-183. http://doi.org/10.5296/ijl.v6i4.4547. 
[28] Wang, W. (2017). From a conditional marker to a discourse marker: The uses of dehua 的话 in natural Mandarin conversation. Journal of Pragmatics 117, 119-138. https://doi.org/10.1016/j.pragma.2017.06.007

[29] Wilson, D. \& Sperber, D. (1994). Outline of relevance theory. Links \& Letters 1, 85-106.

Maram S. Alshammary received her BA in English language in 2015 from the College of Arts, Hail University in Hail, Saudi Arabia. She received her MA in Linguistics in 2019 from the College of Languages and Translation at Al-Imam Mohammed Bin Saud Islamic University, Riyadh, Saudi Arabia.

She has a total of four-year experience in teaching English for EFL learners. She is currently working as an English Language Instructor in the preparatory year of Hail University in Hail, Saudi Arabia. She has published one article. Her current research interests focus on different fields of linguistics including CALL, language acquisition, pragmatics and sociolinguistics. 